\title{
Test Case Analysis with Keyword-Driven Testing Approach Using Katalon Studio Tools
}

\author{
Case Study: Angkasa Website
}

\author{
Reynaldi Prama Octavially ${ }^{1}$, Rosa Reska Riskiana ${ }^{2}$, Kusuma Ayu Laksitowening ${ }^{3}$, Dana Sulistyo \\ Kusumo $^{4}$, Monterico Adrian ${ }^{5}$, Nungki Selviandro ${ }^{6}$ \\ School of Computing, Telkom University, Bandung, Indonesia \\ ${ }^{1}$ reyoctavially@student.telkomuniversity.ac.id, ${ }^{2}$ rosareskaa@telkomuniversity.ac.id, \\ ${ }^{3}$ ayu@telkomuniversity.ac.id, ${ }^{4}$ danakusumo@telkomuniversity.ac.id, ${ }^{5}$ monterico@telkomuniversity.ac.id, \\ ${ }^{6}$ nselviandro@telkomuniversity.ac.id
}

Accepted 15 December 2021

Approved 22 January 2022

\begin{abstract}
Testing a software is an important stage of a series of software development. Functional testing of each feature on the Angkasa Website is intended to try out the function to match the required specifications. To achieve a functional test result, there are elements of features on the web page that require keywords. These keywords are used to perform actions or actions in running a web page, these keywords will help in making Test Cases for the testing process. Because it takes the right keywords to test on the web. To overcome this problem, this study analyzes the use of the Keyword Driven Testing approach for making Test Cases through the Katalon Studio tools. Keyword Driven Testing is one of the concepts in ISO/IEC/IEEE 29119, namely Keyword Driven Testing in The Test Design Process. The results of the analysis show that making Test Cases with Keyword Driven testing is easier to understand and is fully supported by the Katalon Studio tools. However, when creating test cases, not all keywords can be added automatically, so they need to be added manually. The automated testing successfully applied 10 keywords to test 26 features on the Angkasa Website with PASSED results for all of its features, but in the manual testing there is 1 bug found on Personal Information page. The difference result is because of Katalon Studio only checks whether the photo appears or not, but doesn't check whether the photo is corrupted or not.
\end{abstract}

Index Terms - Automated Testing; Katalon Studio; Keyword Driven Testing; Test Cases; Website.

\section{INTRODUCTION}

Software testing is one of the most important stages in the manufacture and development of a software, this test is carried out to determine the quality and feasibility of the software being developed. Ensure that the software being developed meets the requirements and is free from bugs and errors [1]. Software Testing is very important because it serves to ensure the quality of a software [2].

Software Testing is the last stage that must be passed in software development, Software quality can only be known through the testing phase, through technological advances throughout the world, there have been many improvements in terms of techniques and methods used to test a software [3]. An important aspect of the testing phase is to make sure the output is correct or not [4].

Website is a software that is widely used for organizational needs as a place to find and share information, a website has become a very powerful communication tool and its success depends on its accessibility, SEO (Search Engine Optimization) and its usability [5]. But not a few websites have problems with some of their features so that the website can't be used fully.

Based on this explanation, all software that is being developed must pass the testing stage before being released and used by users so that the software can run properly and not have problems that can confuse and disappoint users.

There are many approaches that can be used in automated software testing, either using a programming language or using a tool that can simplify the testing process. One approach that can be used is KeywordDriven Testing in The Test Process which is a concept from ISO/IEC/IEEE 29119. This concept aims to support the conversion of keyword-based test cases into various types of test scripts that can be automatically executed by tools used [6].

There are many methods that can be used in automated testing of software, one of which is using Behavior Driven Development (BDD), which is a method that describes what activities need to be carried out in software testing and has the advantage of displaying information so that it can be easily understood by members. Project team and business team [7]. But if there are changes to the website that is being tested, it will take a long time to change back the tests that have been done previously, in contrast to testing using Keyword Driven Testing. In KeywordDriven Testing, all the keywords used for testing a 
website can be easily added, removed and modified so that if there are changes to the website, the test does not need to be done from scratch [8]. By using KeywordDriven Testing, the tests created can be easier to maintain and allow for easy understanding so that all team members can work together to carry out the test [9]. Therefore, this paper aims to analyze the implementation of Keyword-Driven Testing to make test cases for testing the Angkasa Website, because the Angkasa website has many features that must go through a testing phase to ensure whether these features are in accordance with the requirements or not, for example, such as the payment feature which involves money, because if this feature is not tested it will harm many parties.

In addition, similar research explains that Keyword Driven Testing saves a lot of manual testing by automating the website testing process for various test cases and also every keyword that has been used can be reused to test different websites [8]. In research on the evolution of Keyword Driven Testing shows that Keyword Driven Testing has a complex design with several levels of abstraction and a design that supports reuse, more than $60 \%$ of keywords used have the potential to reduce changes required during evolution by up to $70 \%$ [9].

In this paper, the researcher will use Katalon Studio to test the Angkasa Website because it is very suitable for beginners who are not used to testing software, Katalon Studio is also easier to use than other tools because in Katalon Studio the testers do not need to write scripts manually, everything is automatic so testing will not take a long time. Katalon Studio provides various features and has detailed, easy-to-read reports that can be presented in various formats such as HTML, CSV and PDF and can be shared with team members at any time [1]. Katalon studio has features that make it easy to use Keyword-Driven Testing, namely the Record and Playback features. The Record and Playback feature is very easy to use for testing a software and also speeds up processing time, so this feature was chosen for testing on the Angkasa Website. The purpose of this research is to find out what keywords will be used for the Keyword Driven Testing method which will then be tested for all the features on the website, whether all these features are ready to use or need to be repaired, all of this can be done through automatic testing using Keyword Driven Testing with keywords that have been obtained using Katalon Studio Tools.

\section{RELATED WORK}

\section{A. Literature Review}

On research [7]-[9] describes the implementation of BDD (Behavior Driven Development) which is integrated with automation testing tools in software development using Katalon Studio Tools. The method used is Keyword Driven Testing which uses keywords to perform a software test, because Keyword Driven Testing is very easy to add and update and does not require much time in the testing process.

Automated testing of software that requires less time and less cost than manual testing is a testing technique using a code to perform machine-driven testing [10]. In Automation Testing, all software testing activities are carried out automatically starting from development, verification, and testing using Automated Testing Tools [11]. Katalon studio is one of the tools that is often used to implement the Keyword Driven Testing method, because Katalon Studio has a feature that makes it easy to find keywords to use [1].

Based on the literature review that has been explained, this research will analyze the result of testing implementation using Keyword Driven Testing to make test cases which is part of BDD using Katalon Studio on Angkasa Website.

\section{B. Keyword Driven Testing}

Keyword Driven Testing has undergone a change which was originally in the form of Scripted Test Automation into a test table with various keywords in it which serves to perform testing on a software.

Keyword Driven Testing is an increasingly popular testing method or approach because it involves the creation of reusable, modular test components. In Keyword Driven Testing, the system testing functionality is packaged in a table and it contains stepby-step instructions for each test [6].

ISO (the International Organization for standardization) and IEC (the International Electrotechnical Commission) have established a special system for standardization in the world, in addition the bodies that are members of ISO or IEC also participate in the development of international standards. [12].

ISO/IEC/IEEE 29119 aims to define a set of internationally agreed standards for software testing that can be used by any organization performing software testing [12]. ISO/IEC/IEEE 29119-5 will explain the main concepts of Keyword Driven Testing.

In Keyword Driven Testing, testing can be carried out more easily and can also be easily corrected if there are changes to the software being tested, Keyword Driven Testing can also allow experts from different fields and backgrounds to work together in different places [9]. To automate testing, each keyword needs to be implemented in the software [13].

- Keyword Rank

In Keyword Driven Testing, the keywords used consist of 2 levels, described as follows [13]:

1. Low Level, at this level the keys are associated with a collection of one or more actions that explain what steps must be 
taken in the testing process. Example: click, set text, select, and others.

2. High Level, at this level keywords require a set of input parameters, which are also included in the structure. Keywords and parameters form a high-level description of the actions associated with the test case. Example: Open browser, login, and others.

\section{- Layers in Keyword Driven Testing}

There are 3 layers in Keyword Driven Testing, explained as follows [13]:

1. Domain Layers

The keywords in Domain Layers correspond to a domain-related business or activity and reflect the terminology used by domain experts. Keywords developed at Domain Layers are generally not implementation dependent.

2. Test Interface Layers

The keywords in Test Interface Layers refer to the type of interface used in a particular test. The actions required to address the test items can usually be easily identified.

3. Multiple Layers

Multiple Layers serves as a container that combines several existing Layers namely Domain and Interface Layers, Multiple layers can help manage hierarchical keywords.

- Keyword Type

There are 2 types of keywords in Keyword Driven Testing. Described as follows:

\section{Simple Keywords}

The simple keyword is a keyword that is often used in Test Interface Layers, such as MenuSelect and PressButton.

\section{Compound Keywords}

Combined keywords are a set of keywords or a keyword that is composed of other keywords, combined keywords can be arranged in different layers.

- Keyword Identification

Keyword Driven Testing requires the identification and definition of keywords. There are several sources that can be used to identify and define keywords, including the following [13]:

\section{Exploration Test}

In exploratory testing, the examiner observes which steps are performed. The new keyword is defined by providing a meaningful name, if the sequence of steps can be used with different data, the keyword will take the appropriate parameters for that data [13].

2. Business Expert

Keywords can be determined by conducting interviews with business experts, this question can be "What should be done to verify the application?" or "what needs to be tested?". The answers given by the experts will be used to identify keywords by finding terms that may appear frequently [13].

3. Interface Test

Keywords can be specified through the test interface, but because interface elements are limited and usually small, a number of keywords can be defined for these interface elements. This approach will define lowlevel keywords in the Test Interface Layers [13].

4. Documented test procedures and test cases

The available test procedures and test cases can also be used as material for determining keywords. If two or more of the keywords found refer to the same activity, those keywords will only be replaced with the one keyword that best describes the activity [13]. Here are the conditions for keywords [13]:

a. Keywords must contain a verb.

b. Keywords must use the imperative form.

c. Keywords should provide a description of a series of related actions.

d. The keyword description should be clear.

e. Keywords must be defined in such a way that they can be understood by stakeholders who will use them when designing tests.

f. Each keyword must be unique in its meaning within a framework.

- Implementation of Keyword Driven Testing

This section discusses several concepts that contribute to the successful implementation of Keyword Driven Testing, there are six concepts discussed in this section, namely [13]:

1. Identifying keywords.

2. Composing test cases 
3. Keywords and data driven testing.

4. Modularity and refactoring.

5. Keyword driven testing in the test design.

6. Converting non-keyword driven cases into keyword driven testing.

\section{Katalon Studio}

Katalon studio is an automation testing tool developed by Katalon LLC released in January 2015 launched on Microsoft Windows, macOS, and Linux. [10]. Katalon studio is built on the Selenium Framework's open-source test automation, Appium using an IDE interface, built specifically for testing web-based, API, mobile, and desktop applications. [7].

Katalon Studio has a comprehensive set of features to implement [14], supports testing using keywords or Keyword Driven Testing which allows users who do not have experience in application testing to do it easily.

\section{MethodOLOGY}

This study applies the concept of Keyword Driven Testing, namely Keyword-Driven Testing in The Test Design as a reference for conducting automated testing on the Angkasa Website. The steps taken are data collection, automatic testing, analysis, and conclusions, as shown in Figure 1.

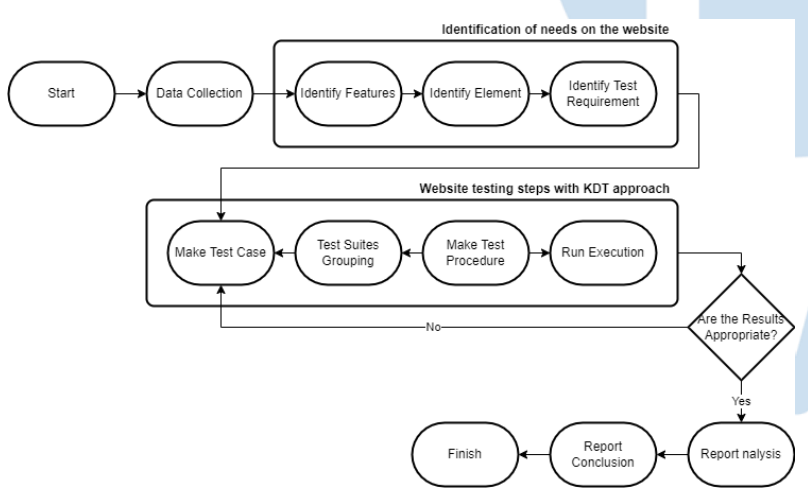

Fig. 1. Research Methods

\section{A. Test Design and Implement Process}

The following are some parts of the test design and implementation process used in the research shown in Figure 1.

\section{- Identify Feature}

Identify feature on the Angkasa Website which will later be tested based on previously created documents. In this step, the examiner will note what features are on the Angkasa Website and will pass the testing stage.

- Identify Element

A collection of special restrictions that contain functionality such as transaction features, functions, or structural elements that exist on the Angkasa Website. In this step, the examiner will record what elements are on the Angkasa Website to be processed in the testing phase.

- Identify Test Requirement

Describe the test requirements at least once. What actually qualifies to be a covered requirement depends on each team's interpretation. In this step, the examiner will record what are the conditions for the test to be said to be successful or not.

Based on the three steps above, automatic testing will then be carried out using the Katalon Studio tools, namely the creation of a Test Case with a Keyword Driven Testing approach, derive Test Suite, test procedures, and program execution. The following are the steps carried out in the research.

\section{- Make Test Case}

Test Cases are generated automatically either from specifications or code [15]. The test case that will be made focuses on positive cases that are adjusted to the acceptance criteria documents from the Angkasa Website. The Test Case is made by determining the keywords to be used in accordance with the Keyword Driven Testing approach, these keywords are determined based on the user story listed in the Software Requirements Specification. The following is an example of keywords obtained from 3 features on the Angkasa Website, the keywords can be seen in table I.

TABLE I. IDENTIFICATION OF KEYWORDS

\begin{tabular}{|c|l|l|}
\hline Feature & \multicolumn{1}{|c|}{$\begin{array}{c}\text { Expected } \\
\text { Behavior }\end{array}$} & Keywords \\
\hline \multirow{5}{*}{ Login } & $\begin{array}{l}\text { Can press the } \\
\text { login button to } \\
\text { enter the login } \\
\text { page. }\end{array}$ & Click \\
\cline { 2 - 3 } & $\begin{array}{l}\text { Can fill in the } \\
\text { username. }\end{array}$ & Set text \\
\cline { 2 - 3 } & $\begin{array}{l}\text { Can fill in the } \\
\text { password. }\end{array}$ & $\begin{array}{l}\text { Set } \\
\text { encrypted }\end{array}$ \\
\cline { 2 - 3 } & $\begin{array}{l}\text { Can login by } \\
\text { pressing the } \\
\text { login button. }\end{array}$ & Click \\
\hline \multirow{5}{*}{ Payments } & $\begin{array}{l}\text { Can choose the } \\
\text { package to be } \\
\text { paid for }\end{array}$ & $\begin{array}{l}\text { Can see the } \\
\text { given payment } \\
\text { code. }\end{array}$ \\
\hline
\end{tabular}




\begin{tabular}{|c|l|l|}
\hline \multirow{1}{*}{} & $\begin{array}{l}\text { Can choose an } \\
\text { available bank. }\end{array}$ & Click \\
\cline { 2 - 3 } & $\begin{array}{l}\text { Can see } \\
\text { payment status }\end{array}$ & $\begin{array}{l}\text { Verify Text } \\
\text { Present }\end{array}$ \\
\hline \multirow{7}{*}{$\begin{array}{l}\text { Edit } \\
\text { Profile }\end{array}$} & $\begin{array}{l}\text { Can press the } \\
\text { edit profile } \\
\text { button }\end{array}$ & Click \\
\cline { 2 - 3 } & $\begin{array}{l}\text { Can delete } \\
\text { profile data field } \\
\text { profile data } \\
\text { fields }\end{array}$ & Clear Text \\
\cline { 2 - 3 } & $\begin{array}{l}\text { Can press save } \\
\text { profile button }\end{array}$ & Click \\
\cline { 2 - 3 } & $\begin{array}{l}\text { Can see } \\
\text { notification that } \\
\text { profile was } \\
\text { successfully } \\
\text { updated }\end{array}$ & $\begin{array}{l}\text { Verify } \\
\text { Element } \\
\text { Present }\end{array}$ \\
\hline
\end{tabular}

Keywords are obtained from every condition that must be met from the features provided. The steps taken to fulfill these conditions have their respective keywords that must be carried out so that these steps can be carried out.

Test Cases are made on the Katalon Studio tools using the record and playback features. Record functions to record every action or keyword performed when using the website, while playback functions to play back every action that has been carried out through the record feature. The following is an example of a Test Case using the record and playback feature with the Keyword Driven Testing approach at Katalon Studio shown in Figure 2.

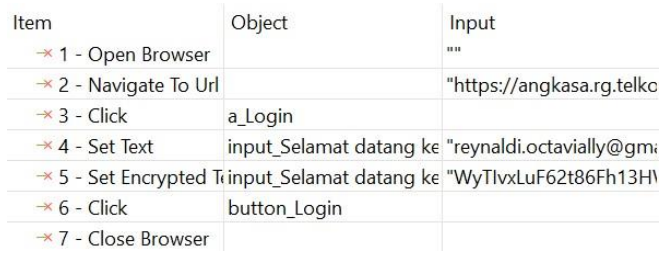

Fig. 2. Katalon Studio Test Case

- Test Suites Grouping

Test Suite is a grouping of tests based on Test Cases that have been created [16]. In Katalon studio, each Test Case can be grouped by page function or all Test Cases on the same page, so that each Test Case that has been made does not need to be executed one by one and does not require a long time. this grouping is called Test Suite as shown in Figure 3.

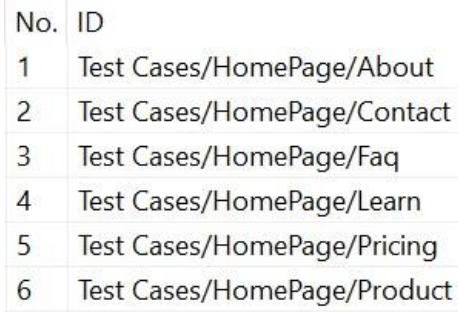

Fig. 3. Katalon Studio Test Suite

- Make Test Procedures

Specifies the order of execution of the entire test set. Test Procedures in this test are based on the user journey. In this test, they are grouped into three parts, namely for Angkasa Home Page, Dashboard, and Personal Information. This is adjusted to the page category provided by the website which is currently in the testing phase.

- Run Execution

Test Cases and Test Suites that have been created and sorted according to the Test Procedure will be executed using Katalon Studio. All Test Cases will be executed after being grouped into Test Suites to get a report from each Test Case created.

\section{RESULT AND DISCUSSION}

After doing research using Keyword Driven Testing, the results and test analysis are as follows:

- Test Result

Based on the tests that have been carried out on the Angkasa Website, it was found that 10 keywords were obtained from Software Requirements Specification and obtained when testing using Katalon Studio. In accordance with the provisions of the ISO/IEC/IEEE 29119 document, keywords are divided into 2 levels, namely high and low. There are 4 keywords that fall into the high category, namely Open Browser, Close Browser, Navigate to Url, and Upload File. As for the low category, there are 6 keywords, namely Click, Set Text, Clear Text, Delay, Verify Element Present, and Verify Text Present. The keywords used can be seen in table II.

TABLE II. Automatic Test Result

\begin{tabular}{|l|l|l|}
\hline Keywords & \multicolumn{1}{|c|}{ Functions } & Level \\
\hline $\begin{array}{l}\text { Open } \\
\text { Browser }\end{array}$ & $\begin{array}{l}\text { Open the browser in } \\
\text { use. }\end{array}$ & \multirow{2}{*}{ High } \\
\cline { 1 - 2 } $\begin{array}{l}\text { Close } \\
\text { Browser }\end{array}$ & $\begin{array}{l}\text { Close the browser in } \\
\text { use. }\end{array}$ & \\
\cline { 1 - 2 } $\begin{array}{l}\text { Navigate } \\
\text { to Url }\end{array}$ & $\begin{array}{l}\text { Open the website } \\
\text { address to be tested. }\end{array}$ \\
\hline
\end{tabular}




\begin{tabular}{|c|c|}
\hline $\begin{array}{l}\text { Upload } \\
\text { File }\end{array}$ & $\begin{array}{l}\text { Upload and save } \\
\text { photos on the } \\
\text { website. }\end{array}$ \\
\hline Click & Press a button or link. \\
\hline Set Text & $\begin{array}{l}\text { Fill in the field with } \\
\text { text. }\end{array}$ \\
\hline Clear Text & Delete text in a field. \\
\hline Delay & $\begin{array}{l}\text { Set the delay time } \\
\text { while testing. }\end{array}$ \\
\hline $\begin{array}{l}\text { Verify } \\
\text { Element } \\
\text { Present }\end{array}$ & $\begin{array}{l}\text { Ensures elements } \\
\text { appear on the page as } \\
\text { they should. }\end{array}$ \\
\hline $\begin{array}{l}\text { Verify } \\
\text { Text } \\
\text { Present }\end{array}$ & $\begin{array}{l}\text { Make sure the text } \\
\text { appears on the page } \\
\text { as it should. }\end{array}$ \\
\hline
\end{tabular}

Test Cases are made using the Record and Playback feature provided by Katalon Studio, this feature can make it easier for testers to test the Angkasa Website and automatically add keywords to the test document. But not all keywords can be added automatically, namely Upload, Verify Element Present and Verify Text Present. Upload is used to upload a file to the website, Verify Element Present serves to ensure an element such as images, text and others appear on a certain page as a sign that the test is successful and as it should be, while Verify Text Present is to ensure the text that appears on a particular page. These three features cannot be added automatically because Record and Playback only record what the user clicks or fills on the web page being tested, so if the command is not a click or fill in a field, it must be edited manually when the test is complete.

Tests are divided into 2 categories, namely successful and failed. The test is said to be successful if the input is correct and the results issued are also appropriate and the system declares the test successful. The test is said to have failed if firstly, the input is correct but the resulting output does not match, and secondly if the input is correct but the output of the system fails. The results of the tests that have been carried out on the Angkasa Website can be seen in table III.

TABLE III. Automatic Test Result

\begin{tabular}{|l|c|c|c|}
\hline \multirow{2}{*}{ Test Suites } & \multirow{2}{*}{$\begin{array}{c}\text { Number of } \\
\text { Test Case }\end{array}$} & \multicolumn{2}{|c|}{ Status } \\
\cline { 3 - 4 } & & Passed & Failed \\
\hline $\begin{array}{l}\text { Angkasa } \\
\text { Home Page }\end{array}$ & 9 & 9 & 0 \\
\hline
\end{tabular}

\begin{tabular}{|l|c|c|c|}
\hline $\begin{array}{l}\text { Angkasa } \\
\text { Dashboard }\end{array}$ & 11 & 11 & 0 \\
\hline $\begin{array}{l}\text { Personal } \\
\text { Information }\end{array}$ & 3 & 3 & 0 \\
\hline
\end{tabular}

The results of automatic testing using Katalon Studio show that all Test Suites are Passed and none are Failed, but different from the manual testing that has been done previously which had 1 failed from 3 Test Case on Test Suites on the Personal Information page. The results of manual testing can be seen in table IV.

TABle IV. Manual Test Result

\begin{tabular}{|l|c|c|c|}
\hline \multirow{2}{*}{ Test Suites } & \multirow{2}{*}{$\begin{array}{c}\text { Number of } \\
\text { Test Case }\end{array}$} & \multicolumn{2}{|c|}{ Status } \\
\cline { 3 - 4 } & & Passed & Failed \\
\hline $\begin{array}{l}\text { Angkasa } \\
\text { Home Page }\end{array}$ & 9 & 9 & 0 \\
\hline $\begin{array}{l}\text { Angkasa } \\
\text { Dashboard }\end{array}$ & 11 & 11 & 0 \\
\hline $\begin{array}{l}\text { Personal } \\
\text { Information }\end{array}$ & 3 & 2 & 1 \\
\hline
\end{tabular}

- Test Analysis

In the test results, it is explained that there are some keywords that cannot be added automatically through the Record and Playback feature at the time of making the Test Case. This is because these keywords are used to ensure that an element appears on the page being tested, so keywords must be entered manually by selecting from a list of keywords provided by Katalon Studio.

By using the Keyword Driven Testing approach for making Test Cases on the Angkasa Website, all the tested features have the status passed and no features failed or failed. In this test there is a problem found by the researcher, namely the number of changes to the structure of the Angkasa Website, for example, such as id, name and also xpath so that when the researcher repeats the test on the same feature, the results will fail because there are changes to the website structure.

Testing by implementing a concept that is part of ISO/IEC/IEEE 29119-2 namely Keyword Driven Testing in The Test Design Process at Katalon Studio is a very appropriate step. Because Katalon Studio is a tool that supports testing using Keyword Driven Testing, because Katalon Studio has provided a list of keywords that can be used in the testing process, katalon Studio also provides Test Suites to group Test Cases based on their respective Page Functions, 
making the Test Case itself is divided into 3 options, namely Record and Payback, manual testing and testing using scripts. The results of automated testing using Katalon Studio for the test suites home page can be seen in Figure 4.

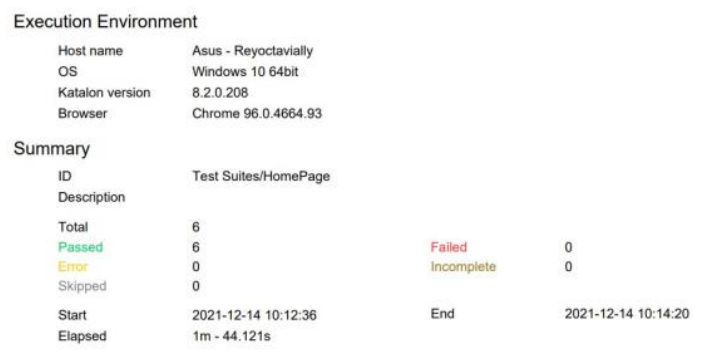

Fig. 4. Automated Testing Result

In the tests that have been carried out there are differences in results between automatic testing and manual testing. If an automatic test is carried out, all the results will get a PASSED status but if a manual test is carried out there is 1 feature that has a FAILED status, this happens because the FAILED status feature does not manage to display an image that matches the image uploaded by the user so it says FAILED is in the test. But the feature is PASSED when automatic testing is performed, that's because the automatic test only checks whether the image appears or not, does not check whether the image is damaged or not.

\section{CONCLUSION}

Keyword Driven Testing is very helpful in the software testing process because it is easy to add, remove and update if there are changes to the content of the website being tested. The identification of keywords to be used can be determined by exploration, business expert interviews, interface tests, and documented test procedures and test cases.

The keywords used in Keyword Driven Testing must comply with predetermined procedures, which must contain a verb, have an imperative form, provide a description and others.

In testing a software, two tests must be carried out, namely manual testing and automatic testing, because the two tests have different results, so it can be concluded that the two tests cannot be separated. Although automatic testing is easier and faster, manual testing can be more thorough and have more accurate results.

In this study, automated testing analysis with Keyword Driven Testing was carried out on the Angkasa Website which is a cloud-based website being developed by Telkom University, testing was carried out using the Katalon Studio tools that fully support Keyword Driven Testing. This study also uses the concept of ISO/IEC/IEEE 29119-2, namely Keyword
Driven Testing in The Test Design Process. The conclusions obtained from this research are:

- Automatic Testing successfully applied 10 keywords that were used to test 26 features on the Angkasa Website with PASSED results for all of its features.

- Manual Testing successfully applied 10 keywords that were used to test 26 features on the Angkasa Website with PASS results for all 25 features and FAILED for 1 feature.

- Keyword Driven Testing in The Test Design Process has been successfully implemented on the Katalon Studio tools by using the Record and Payback features to make it easier to search, add, and use the required keywords. Katalon Studio provides a list of keywords that are ready to be used for the Record and Playback feature, manual testing or testing using scripts.

- The keywords that Katalon Studio can't read automatically are because they don't give any action but only as a marker if an element is successfully displayed and indicates a successful test.

Execution between Test Cases requires a time lag to avoid arbitrary results.

\section{ACKNOWLEDGEMENT}

This work was part of matching fund Kedaulatan Indonesia dalam Reka Cipta (Kedaireka) - Kampus Merdeka supported by Kementrian Pendidikan dan Kebudayaan Republik Indonesia, Jakarta 10270.

\section{REFERENCES}

[1] E. Pelivani and B. Cico, "A comparative study of automation testing tools for web applications," Jun. 2021. doi: 10.1109/MECO52532.2021.9460242.

[2] X. Meng, "Analysis of Software Automation Test Protocol," 2011.

[3] SKR Engineering College, Institute of Electrical and Electronics Engineers. Madras Section, and Institute of Electrical and Electronics Engineers, International Conference on Energy, Communication, Data Analytics \& Soft Computing (ICECDS) - $2017:$ 1st \& 2nd August 2017

[4] United International College, IEEE Computer Society, and Institute of Electrical and Electronics Engineers, Proceedings of 2015 IEEE International Conference on Teaching, Assessment and Learning for Engineering (TALE) : date and venue: 10-12 December 2015, United International College, Zhuhai, China.

[5] Jouf University and Institute of Electrical and Electronics Engineers, 2019 International Conference on Computer and Information Sciences (ICCIS) : Jouf University - Aljouf kingdom of Saudi Arabia, 03 - 04 April 2019

[6] Jingfan Tang, Xiaohua Cao, and Albert Ma, Proceedings of the IEEE International Conference on Automation and Logistics : Qingdao, China September 2008. IEEE Xplore, 2008.

[7] U. Nugraha, S. Atikah Nurduha Robaiah, and D. Rospinoedji, "Testing The Information System Software Using Behavior Driven Development Method," Palarch's Journal Of Archaeology Of Egypt, vol. 17, no. 10, 2020. 


\section{ISSN 2085-4552}

[8] R. Gupta and N. Bajpai, "A keyword-driven tool for testing web applications (KeyDriver)," IEEE Potentials, vol. 33 , no. 5, pp. 35-42, Sep. 2014, doi: 10.1109/MPOT.2012.2202135.

[9] R. Rwemalika, M. Kintis, M. Papadakis, Y. le Traon, and P. Lorrach, "On the evolution of keyword-driven test suites," in Proceedings - 2019 IEEE 12th International Conference on Software Testing, Verification and Validation, ICST 2019, Apr. 2019, pp. 335-345. doi: 10.1109/ICST.2019.00040.

[10] N. Srivastava, U. Kumar, P. Singh, and P. Singh, "Software and Performance Testing Tools," Journal of Infor-matics Electrical and Electronics Engineering, vol. 02, no. 001, pp. 1-12, 2021.

[11] Institute of Electrical and Electronics Engineers., 2012 7th International Workshop on Automation of Software Test (AST) : proceedings : June 2-3, 2012, Zurich, Switzerland. IEEE, 2012.

[12] I. Computer Society and S. C. Engineering Standards
Committee, "Software and systems engineering-Software testing-Part 3: Test documentation Ingénierie du logiciel et des systèmes-Essais du logiciel-Partie 3: Documentation des essais," 2013.

[13] International Electrotechnical Commission, Institute of Electrical and Electronics Engineers, and International Electrotechnical Commission. Technical Committee 91, Standard for automatic test markup language (ATML) test adapter description.

[14] B. Bhagat, S. Bhattacharjee, and S. Ratre, "Software Testing Techniques \& Automation Tools," Mukt Shabd J., vol. 9, no. 5, pp. 5957-5962, 2020, doi: 09.0014.MSJ.2020.V9I5.0086781.104235

[15] M. Mirzaaghaei, F. Pastore, and M. Pezzè, "Supporting Test Suite Evolution through Test Case Adaptation," 2012, doi: 10.1109/ICST.2012.35.

[16] Ahlam S. A. Ansari, Kailas K. Devadkar, and Prachi Gharpure, "Optimization of test suite-test case in regression test," 2013. 